\title{
A CRIAÇÃO DE UM FUNDO DE EQUALIZAÇÃO DE RECEITAS PARA A CFEM COMO ESTRATÉGIA DE JUSTIÇA INTERGERACIONAL EM MUNICÍPIOS MINERADORES DO PARÁ
}

\author{
Ana Elizabeth Neirão Reymão* \\ Marcos Venancio Silva Assunção** \\ Alsidéa Lice de Carvalho Jennigs Pereira***
}

\section{RESUMO:}

O objetivo do artigo é discutir a importância de um fundo de equalização de receita como alternativa para a gestão financeira dos recursos da CFEM. Indaga o texto se eles podem ser estratégias de desenvolvimento e de justiça distributiva das riquezas minerais para as futuras gerações. A pesquisa é qualitativa, sendo o estudo exploratório e descritivo, baseado em fontes bibliográficas e documentais. Como base nos princípios igualitários de justiça de John Rawls na ideia de justiça intergeracional de Joerg Tremmel (2009), conclui-se que eles podem ser importantes para a promoção do desenvolvimento sustentável nos municípios mineradores paraenses.

Palavras-chave: Fundo de equalização de receitas. CFEM. Desenvolvimento. Mineração. Solidariedade Intergeracional.

\section{THE CREATION OF A REVENUE EQUALIZATION FUND FOR CFEM AS A STRATEGY FOR INTERGENERATIONAL JUSTICE IN MINING MUNICIPALITIES OF PARÁ}

\section{ABSTRACT:}

The paper discusses the importance of a revenue equalization fund as an alternative for the financial management of CFEM resources. Can they be strategies for the development and distributive justice of mineral wealth for future generations? The research is qualitative and the study is exploratory and descriptive, using bibliographic and documentary sources. Based on the egalitarian principles of justice by John Rawls and in the idea of intergenerational justice by Joerg Tremmel (2009), it is concluded that the funds can be important for the promotion of sustainable development in the mining towns of Pará.

Keywords: Revenue equalization fund. CFEM. Development. Mining. Intergenerational Solidarity.

\footnotetext{
*Economista (UFPA), Doutora em Ciências Sociais (UnB), Mestre em Economia (UNICAMP). Professora do Programa de Pós-Graduação em Direito, Políticas Públicas e Desenvolvimento (PPGD) do CESUPA e da Faculdade de Economia da UFPA. Líder do grupo de pesquisas CNPq MinAmazônia (Mineração e Desenvolvimento Regional na Amazônia). E-mail: bethrey@uol.com.br

** Mestrando do Programa de Pós-Graduação em Direito, Políticas Públicas e Desenvolvimento do CESUPA. Bacharel em Direito e assessor de gabinete do $2^{\circ}$ Ofício Regional da DPU/PA. Grupo de pesquisas CNPq MinAmazônia (Mineração e Desenvolvimento Regional na Amazônia). E-mail: mvenan@ gmail.com

**** Mestranda do Programa de Pós-Graduação em Direito, Políticas Públicas e Desenvolvimento do CESUPA. Grupo de pesquisas CNPq MinAmazônia (Mineração e Desenvolvimento Regional na Amazônia). E-mail: alsidealice@hotmail.com
} 


\section{Introdução}

Em 2019, o Pará passou a ser o maior arrecadador nacional de Compensação Financeira pela Exploração de Recursos Minerais (CFEM), com valor superior a $\mathrm{R} \$ 2$ bilhões, representando quase $49 \%$ do total nacional (ANM, 2020), o que evidencia a importância da mineração no estado.

Seus principais polos produtivos concentram-se nas regiões sul e sudeste, onde funcionam os projetos comerciais minerários mais expressivos da região, a saber: Canaã dos Carajás, Parauapebas e Marabá, sendo destacada também a produção em municípios como Oriximiná e Paragominas. Esse rol deve aumentar pois, de acordo com as metas estaduais estabelecidas para o setor, há uma previsão de que, até 2030, 38 novas cidades mineradoras sejam incluídas ao grupo de 55 em operação até o momento, ampliando ainda mais o volume de exportações e de receitas da CFEM incorporadas aos orçamentos públicos (SEICOM, 2014).

A relevância desses recursos é inegável, ajudando a reequilibrar as contas públicas dos municípios, assim como as exportações geram superávits comerciais para o país. No entanto, embora a produção mineral tenha impacto financeiro significativo nas receitas desses entes federativos, a literatura mundial aplicada ao tema vem alertando sobre os danos multidimensionais trazidos às regiões que abrigam grandes empreendimentos de extração minerária (CONGILIO, 2019). E mais, a dinâmica local tende a depender quase que exclusivamente dela, encolhendo os demais setores da cadeia produtiva e impedindo o desenvolvimento sustentável local intra e intergeracionalmente, fenômeno considerado por parte da doutrina como uma espécie de maldição dos recursos minerais finitos (ENRIQUEZ, 2007).

Reduzir os efeitos danosos da mineração e deixar, como legado solidário, parte dos benefícios auferidos com o recebimento dessa Compensação, para as futuras gerações, constitui-se hoje, um grande desafio para os sucessivos governos responsáveis pela administração pública nos próximos anos.

Assim, a presente pesquisa tem como objetivo discutir a importância dos Fundos de Equalização de Receitas (FER) como alternativa para a gestão financeira dos recursos da CFEM, que viabilize o desenvolvimento sustentável dos municípios mineradores paraenses e promovam a formação de uma poupança capital promotora de justiça intergeracional. 
A constituição dos FER é inspirada nos fundos soberanos de riquezas (FSR), os quais podem ter um grande número de objetivos, dentre os quais economizar recursos para as gerações futuras, organizados como fundos de desenvolvimento para atingir vários objetivos socioeconômicos (TRUMAN, 2010).

O problema de pesquisa é: "podem os FER ser estratégias de desenvolvimento e justiça distributiva das riquezas minerais para as futuras gerações?”. O estudo é de abordagem qualitativa, sendo a pesquisa exploratória e descritiva, baseada em fontes bibliográficas e documentais. O texto traz, no entanto, informações dos bancos de dados da Agência Nacional de Mineração (ANM) e do Finanças do Brasil (Finbra), com o fito de mensurar a importância das receitas de CFEM nos orçamentos municipais e subsidiar a discussão em favor da necessidade de bem administrá-las.

Como referência teórica desse estudo, adota-se a ideia de justiça como equidade de John Rawls (2000) e a teoria de justiça intergeracional de Joerg Tremmel (2009), tema da seção dois do texto, apresentada após essa introdução. A seção três discute a CFEM e sua importância para as sucessivas gerações. Na seção quatro apresenta-se a ideia dos fundos públicos municipais. A parte final traz as conclusões do artigo.

\section{Sustentabilidade e justiça intergeracional}

Nenhuma questão foi tão debatida de Platão a Kant como o conceito de justiça, destaca Hans Kelsen (2001). Falta, no entanto, um consenso para sua definição, restando aos indivíduos apenas formular a melhor pergunta. Assim, durante muito tempo, a tradição utilitarista foi o modelo dominante, até que o filósofo norte-americano John Rawls propôs um novo olhar para essa concepção.

Nesse modelo alternativo de Teoria da Justiça, a diretriz teórica descreve o justo como um fator de cooperação social, ou seja, tem-se uma ideia da justiça como equidade, que ficou conhecida como Igualitarismo. Essa proposta reivindica um compromisso de cooperatividade entre os indivíduos para o desenvolvimento de uma sociedade cujos valores são a liberdade, igualdade, solidariedade, satisfação e respeitabilidade (RALWS, 2000).

O autor adota, como ponto de partida, uma situação hipotética, não histórica, de igualdade inicial de liberdades entre os indivíduos que, para exercê-las, firmam um acordo 
social para a vida em comunidade segundo o qual se imagina uma espécie de neocontratualismo, uma releitura do contratualismo jusnaturalista.

Nele, a instauração de uma sociedade politicamente organizada dar-se-ia não apenas pelo contrato, mas pela estruturação racional de regras sociais, fundadas no princípio de uma justiça igualitária. Esse regramento não se destina a um bem privado de cada indivíduo, mas às instituições sociais de forma objetiva, visando a convivência social e o bem comum (RAWLS, 2000).

Ao que se dedica o presente estudo, é importante destacar que a noção de justiça como equidade, proposta por John Rawls está voltada para as instituições, para a coletividade. Trata-se, portanto, de uma justiça que só é possível porque pode ser aplicada pelas instituições primárias de uma sociedade, que, para o autor, representa um modelo capaz de ser concretizado pela estrutura mais básica de uma sociedade democrática, constitucionalmente estabelecida.

Esse igualitarismo tem como base principiológica a garantia de direitos fundamentais dos indivíduos, contemplados nos ordenamentos jurídicos dos Estados democráticos ocidentais, e reivindica o princípio da diferença, no qual as vantagens e desvantagens presentes nas desigualdades sociais podem ser equilibradas pela promoção de oportunidades iguais de acesso ao desenvolvimento e à sustentabilidade.

$\mathrm{Na}$ perspectiva Rawlsiana, os cidadãos em um ambiente democrático, firmam acordos indispensáveis de condições de justiça que os possibilitam avanços em suas capacidades morais, dentro de um convívio razoavelmente equilibrado. Tais acordos são sintetizados nos documentos constitucionais de cada sociedade e representam um modelo de organização social justa e igualitária ideal, a ser adotado por uma sociedade responsável e comprometida com valores e ideais democráticos.

Isso implica a existência de uma racionalidade pública, que pode ser aplicada em estudos acerca da sustentabilidade do desenvolvimento. Zambam e Boff (2013) mostram que o comprometimento das sociedades democráticas em Rawls (2000), expresso como consenso da razão pública em seus documentos normativos, forma um ordenamento social harmônico, porém em constante tensão de interesses divergentes, o que exige que seus cidadãos estejam motivados e de acordo quanto à formação de suas políticas de desenvolvimento sustentável.

Para os autores, aquilo que uma sociedade precisa e anseia para o futuro está contido na racionalidade pública, a qual pode definir os limites de atuação no presente, os recursos à 
disposição e os provimentos para o futuro. Seria na formação da racionalidade pública que se concentram as necessidades reais das múltiplas forças representativas de uma sociedade que pretende se desenvolver para a sustentabilidade.

Nesse sentido, a concepção de Rawls (2000) vincula-se ao problema de pensar a justiça considerando as gerações futuras ${ }^{1}$. No entanto, conceber uma justiça sobre direito e deveres que possam ser aplicados a diferentes gerações não é tarefa fácil, pois há uma série de problemas imensuráveis que trazem complexidade do tema, mas que inevitavelmente deve ser tratado.

Rawls (2000) entende que o problema da justiça entre gerações submete as teorias sobre ética a exames rigorosos, senão impossíveis de avaliação, posto que as sucessivas gerações, além de manterem as instituições justas, precisam cultivar uma poupança capital (cultura, tecnologia, educação, recursos naturais) para o futuro, como forma de preservação de seus ganhos civilizatórios atuais.

Para o autor, essa transferência do legado é virtual, efetuada a partir do "véu de ignorância", em que cada parte não sabe exatamente a que geração pertence, ou em que estágio civilizatório está sua sociedade. Também não há como saber se uma determinada sociedade é rica, pobre, predominantemente industrial ou agrícola. Diante dessas limitações, cada geração deve poupar igualmente para a outra o que for devido, de forma a compensar os encargos transferidos, que do contrário, podem gerar às futuras gerações, finanças públicas insustentáveis e consequentemente, danos aos direitos fundamentais das próximas civilizações (RAWLS, 2000).

Nessa senda, sua concepção de justiça como equidade intergeracional foi seminal para que o tema fosse debatido por outros pensadores e considerado em diferentes ramos de estudo. Essa noção de justiça intergeracional discutida por Rawls (2000) pode subsidiar a criação de fundos públicos, como os Fundos de Equalização de Receitas (FER), com as rendas da CFEM, a serem tratados mais adiante neste estudo, justamente porque falar em princípios igualitários de justiça implica pensar também nos interesses de gerações futuras, os quais devem ser considerados nas tomadas de decisões públicas, inclusive no que diz respeito

\footnotetext{
${ }^{1}$ Para que se compreenda melhor a ideia de "geração", adota-se aqui a perspectiva de Rocha (2012, p.133), que define o termo como "o conjunto de pessoas nascidas num mesmo lapso temporal que outras, de modo a que se possa distinguir os que já não vivem (gerações passadas), os maiores que vivem (geração presente), e os menores que vivem e os que ainda nascerão (geração e gerações futuras)".
} 
à formulação de políticas públicas em municípios muito dependentes de recursos finitos, como os minerais.

Essa perspectiva de uma justiça intergeracional a partir das discussões rawlsianas tomou a atenção de outros estudos sobre o tema desde a década de 1970, ganhando atenção particular na obra de Tremmel (2009), como em "A Theory of Intergenerational Justice", que destaca como elemento central a demanda de que escolhas presentes devem possibilitar melhorias para a próxima geração.

Está claro para Tremmel (2009) que, na atualidade, a força humana de intervenção no ecossistema exige das gerações presentes um pensar no futuro de forma mais responsável e abrangente. Para o autor, tal responsabilidade, prescinde uma ética intergeracional que considere o acautelamento da própria existência do futuro e evite decisões que sejam irreversíveis, retirando das novas gerações a capacidade de poderem conduzir seu destino ou mesmo a possibilidade de desfrutarem de condições mínimas de vida digna. Nesse contexto, faz-se necessário identificar medidas que possam garantir a distribuição igualitária dos recursos naturais, financeiros, sociais ou institucionais entre as gerações.

É importante destacar, ainda, que a Teoria da Justiça Intergeracional de Tremmel (2009) é ampla e acompanha a perspectiva atual de multidimensionalidade do desenvolvimento sustentável, ou seja, entende a responsabilidade das presentes gerações, para além da questão meramente ambiental. Aplicada ao caso da mineração, como propõe esse artigo, considera outros fatores que promovem ou impedem o desenvolvimento sustentável, decorrentes da exploração de recursos naturais finitos.

Dessa forma, a ideia de sustentabilidade aqui proposta implica no equilíbrio de dimensões distintas de desenvolvimento, sendo possível a compensação do esgotamento do capital natural (sustentabilidade fraca), pelo capital produzido pela ação humana, sem deixar de admitir que possa haver também, complementaridade entre esses recursos (SERAGELDIN, 1995).

\section{A CFEM e sua importância para as sucessivas gerações}

A dinâmica de crescimento econômico e as inovações tecnológicas implementadas a partir da segunda metade do século XX alavancaram a capacidade de exploração dos recursos naturais finitos a quantidades até então inimagináveis, dentro de um curto espaço de tempo. Com isso, os problemas decorrentes da percepção das relações entre a economia, os recursos 
naturais e o meio ambiente levaram os agentes e atores a vislumbrarem um risco de esgotamento dos recursos naturais, com o agravamento dos danos causados ao meio ambiente.

Os governos de regiões minerárias, por exemplo, têm sido alertados que, no ritmo atual de exploração, suas riquezas logo tendem a se esgotar e isso pode ser um grande problema no presente e futuro, posto que, segundo Geoffrey Heal (2004), a sustentabilidade econômica de uma nação rica em recursos minerais, constitui-se em insustentabilidade, ao se portar de forma dependente, de uma renda categoricamente finita. Nessa toada, o autor critica os métodos de medição de riqueza dos estados mineradores pelo Produto Interno Bruto (PIB) que, em grande parte, superestimam estatísticas deturpando interpretações sobre os impactos nocivos provenientes da exploração. Assim, ignorar a exaustão desses recursos, utilizando suas rendas para o consumo, consiste em desperdiçar capitais. É como vender o patrimônio da família e gastar o dinheiro, sem transformá-lo em uma fonte de renda.

O Brasil possui território vasto e privilegiado, mas marcado por um histórico de exploração predatória de seus recursos naturais, esgotáveis, que desde os tempos coloniais, trazendo encargos geracionais de longo prazo em muitas dimensões (FIGUEIRÔA, 2006). Até 1988, não havia imposição normativa constitucional que salvaguardasse os direitos das futuras gerações.

Assim, embora o país não figure entre as constituições citadas por Axel Gosseries (2008) como aquelas que garantem direitos às gerações futuras, a exemplo da do Japão (1946), da Noruega (1992) e da Bolívia (2002), com ela veio a busca pela proteção do direito de todos ao meio ambiente ecologicamente equilibrado. Seu art. 225 o impôs como um bem a ser defendido pelo poder público e pela coletividade, visando o benefício das gerações presentes e futuras. E o dispositivo vai além, ao resguardar o patrimônio genético, os processos ecológicos essenciais, entre outras medidas de proteção (BRASIL, 1988).

No seio da discussão sobre a sustentabilidade, algumas iniciativas de natureza política e legislativa, preocupadas com a questão intergeracional, têm sido implementadas no Brasil, em todos os níveis federativos, ainda que de forma incipiente. Celebra-se, assim, a inclusão da perspectiva de responsabilidade intergeracional para o uso desses recursos no regramento constitucional brasileiro.

Uma delas é a cobrança dos royalties minerais, na forma da Compensação Financeira pela Exploração de Recursos Minerais (CFEM), a ser paga por quem explorar esses recursos 
naturais, na forma do art. 20, $\S 1^{\circ}, \mathrm{CF}^{2}$ (BRASIL, 1988). Ela foi instituída pelas Leis $\mathrm{n}^{\circ}$ 7.990/1990 e 8.001/1990, alteradas pela Lei no 13.540/2017.

O texto constitucional de 1988, é importante frisar, estabeleceu que as jazidas e os depósitos minerais constituem bens da União, distinguindo a propriedade do solo da do subsolo, conforme artigo $176^{3}$. Assim, essa Compensação é uma receita originária do Estado brasileiro e, como receita patrimonial, envolve a exploração do patrimônio público, sendo, nesse caso, um pagamento decorrente da exploração dos recursos minerais por quem explora um direito que pertence à União (SCAFF, 2014).

Não se trata, pois, de um tributo, mas de uma parcela do capital mineral que vai se exaurindo com o tempo de exploração. Nem deve ser confundida com as compensações ambientais (pelo dano causado por instalação das minas), muito menos com as socioambientais, ambas exigidas como parte do licenciamento de exploração junto ao IBAMA ou junto às Secretarias Estaduais de Meio Ambiente (ENRIQUEZ, 2018).

Com a Lei 13.540, que regulamenta a CFEM desde 18 de dezembro de 2017, mudanças significativas foram introduzidas em sua cobrança. Dentre elas, a alteração da base de cálculo, que antes incidia sobre líquida das vendas, e passou a incidir sobre a receita bruta. Além disso, as deduções dos impostos passaram a ser cobradas sobre a comercialização da produção. Outra mudança importante foi a forma de repartição das receitas: a União, de 12\%, passou a receber $10 \%$; nos estados a queda foi de $23 \%$ para $15 \%$, enquanto nos municípios produtores que levavam 65\% da fatia, agora recebem 60\% (BRASIL, 2017).

Referida lei estabeleceu, ainda, que parte dos recursos devem ser preferencialmente aplicados em atividades de diversificação econômica, desenvolvimento do minério sustentável e desenvolvimento da ciência e tecnologia ${ }^{4}$ (BRASIL, 2017).

A Agência Nacional de Mineração (ANM) é o órgão federal responsável pela fiscalização e arrecadação das mineradoras, bem como pela distribuição da CFEM aos entes

\footnotetext{
${ }^{2}$ Art. 20. São bens da União: (...)

$\S 1^{\circ}$ - É assegurada, nos termos da lei, aos Estados, ao Distrito Federal e aos Municípios, bem como a órgãos da administração direta da União, participação no resultado da exploração de petróleo ou gás natural, de recursos hídricos para fins de geração de energia elétrica e de outros recursos minerais no respectivo território, plataforma continental, mar territorial ou zona econômica exclusiva, ou compensação financeira por essa exploração.

${ }^{3}$ Art. 176. As jazidas, em lavra ou não, e demais recursos minerais e os potenciais de energia hidráulica constituem propriedade distinta da do solo, para efeito de exploração ou aproveitamento, e pertencem à União, garantida ao concessionário a propriedade do produto da lavra.

${ }^{4}$ Lei $13.540 / 2017$, Art. $2^{\circ}$, $\S 6^{\circ}$ : Das parcelas de que tratam os incisos V e VI do $\S 2^{\circ}$ deste artigo, serão destinados, preferencialmente, pelo menos $20 \%$ (vinte por centro) de cada uma dessas parcelas para atividades relativas à diversificação econômica, ao desenvolvimento mineral sustentável e ao desenvolvimento científico e tecnológico.
} 
federados. Ela entra no orçamento de estados, municípios e Distrito Federal, mensalmente, a título de Transferências Constitucionais, repassadas pela União. Ao ingressar no orçamento desses entes, o crédito passa a compor o conjunto de suas receitas - impostos, taxas e transferências, algumas delas constitucionais, como é o caso da saúde, educação e do Fundo de Participação dos Municípios (FPM), entre outras voluntárias - previstas na Lei Orçamentária Anual (LOA).

A cobrança da CFEM representou, aos governos proprietários de jazidas minerais, um incremento considerável em suas receitas. Em 2017, o país arrecadou cerca de $\mathrm{R} \$ 1,84$ bilhões, valor que cresceu, aproximadamente, 65\% em 2018 (R \$ 3,04 bilhões) e 145\% em 2019 (R \$ 4,50 bilhões) ${ }^{5}$ (AGÊNCIA NACIONAL DE MINERAÇÃO, 2020).

Sendo uma renda mineral paga como contraprestação pelo usufruto de um recurso natural não renovável, tem representado volumosas quantias, especialmente, nos orçamentos dos municípios onde ocorre a produção mineral (REYMÃO; LOUREIRO; MELLO NETO, 2019). Esses municípios, estão, em maioria, nos estados do Pará e de Minas Gerais ${ }^{6}$ sendo, historicamente, expressivas as arrecadações de Parauapebas (25,7\% do total, em 2019) e de Canaã dos Carajás (15,7\%).

Tabela 1. Receita de CFEM nos dez municípios com maiores arrecadações no Brasil (2018)

\begin{tabular}{|c|c|c|}
\hline Município - UF & CFEM & \% das Receitas Correntes \\
\hline Parauapebas - PA & $\mathrm{R} \$ \quad 400.551 .963,89$ & $32,10 \%$ \\
\hline Canaã dos Carajás - PA & $\mathrm{R} \$ 177.274 .396,34$ & $48,70 \%$ \\
\hline Congonhas - MG & $\mathrm{R} \$ 96.378 .003,66$ & $24,60 \%$ \\
\hline Itabira - MG & $\mathrm{R} \$ \quad 98.044 .283,56$ & $19,60 \%$ \\
\hline Nova Lima - MG & $98.920 .170,73$ & $16,90 \%$ \\
\hline Conceição do Mato Dentro - MG & $23.567 .489,68$ & $21,40 \%$ \\
\hline São Gonçalo do Rio Abaixo - MG & $64.332 .250,66$ & $35,00 \%$ \\
\hline Marabá - PA & $76.420 .659,38$ & $8,70 \%$ \\
\hline Itabirito - MG & $74.410 .644,16$ & $25,80 \%$ \\
\hline Mariana-MG & $61.757 .485,18$ & $21,20 \%$ \\
\hline
\end{tabular}

Fonte: Finanças do Brasil - Finbra (2020)

Considerando o ano de 2018, observa-se uma alta dependência das receitas de CFEM em Canãa dos Carajás (48,7\%), São Gonçalo do Rio Abaixo (35\%) e Parauapebas $(32,1 \%)$. Essa dependência também foi expressiva nos municípios de Itabirito, Congonhas, Conceição

\footnotetext{
${ }^{5}$ Dados em valores correntes.

${ }^{6}$ Em 2019, o Pará foi o maior arrecadador nacional de CFEM (49\% do total), com valor superior a R\$ 2 bilhões. Minas Gerais ficou bem próximo e ocupou o segundo lugar (41\%), tendo sua arrecadação ficado em torno de $\mathrm{R} \$$ 1,8 bilhões (ANM, 2020).
} 
do Mato Dentro, Mariana e Itabira. Nos casos de Nova Lima (16,9\%) e Marabá $(8,7 \%)$ a dependência foi menor.

Como se observa, a relevância dos royalties para essas localidades é inegável. As divisas geradas também, uma vez que os valores ajudam tanto a reequilibrar as contas públicas (internas), devido a superávits financeiros, identificados principalmente no orçamento dos municípios arrecadadores, como a gerar superávits na balança comercial (saldo externo).

Em meio a essa sensação riqueza aparente é que emergem alguns problemas. Por depender do volume de produção comercializado pelas mineradoras, essas receitas podem variar constantemente, devido a fatores internos e externos, a exemplo das crises nas empresas de mineração, desastres ambientais, oscilações de mercado, condições climáticas, tecnologias, crises sanitárias, entre outros (ENRÍQUEZ et al., 2018).

Outra característica importante é que esses royalties minerais constituem valores voláteis pelas oscilações cambiais de mercado e se depreciam pela desigualdade no relacionamento empregado aos países que exportam produtos primários, com a deterioração dos termos de troca. Dessa forma, quem vende bens primários e compra bens manufaturados reduz seu poder de compra, e gera menos renda, favorecendo transferências financeiras para centros industrializados e sua evolução técnica, formando um círculo vicioso (BERCOVICI, 2011).

Por essas razões, qualquer política pública ou regramento jurídico a respeito do uso dessa renda precisa estar alinhada à vontade institucional de potencialização desses recursos, com vistas à sustentabilidade responsável de perspectiva intergeracional. Nesta senda é que se retoma a razão pública proposta em Rawls (2000) como fundamento da valoração de políticas públicas de desenvolvimento e sua atuação como alicerce e efetivação das condições de justiça.

No entanto, o volume auferido em royalties criam expectativas utópicas de prosperidade e medidas econômico-administrativas que, em geral, estão desalinhadas da ideia de sustentabilidade. Ou seja, muitos governos tendem a gastar sem estarem atentos à finitude dos recursos minerais e à limitação dessas receitas. É por isso que alguns autores vislumbram na atividade mineradora realidades paradoxalmente negativas, uma espécie de maldição, um estigma causado preponderantemente por condutas de aspecto político-institucional (KARL, 2007). 
Destaca Enriquez (2007) que a tese de mineração como uma maldição das regiões mineradoras tem sido objeto de vários estudos, os quais mostram que tais economias possuem desempenhos inferiores, se comparadas às que não abrigam recursos minerais. Lewis Jr. (1984) aponta como indicadores de maldição: a má distribuição da renda, a baixa diversidade econômica, exportações concentradas em produtos primários e taxas de crescimento econômico de setores não-mineiros, menores que as de outras economias não-mineradoras.

Essa tese, ao lado de vários exemplos históricos preocupantes ${ }^{7}$, exerce papel importante na discussão acerca da redução dos impactos negativos da exploração mineral e deve ser enfrentada na gestão sustentável das receitas auferidas com a exploração de recursos naturas. Seus efeitos pedagógicos devem alertar grandes economias mineradoras para o desenvolvimento de estratégias de redução desses impactos.

Nesse contexto, é mister que o Estado brasileiro e, por analogia, os estados e municípios mineradores, assumam um modelo de justiça intergeracional e implementem políticas públicas de superação do subdesenvolvimento ${ }^{8}$. Nesse ponto, entra em cena a necessidade de uma gestão sustentável da CFEM de forma que sua destinação desmonte o ciclo de dependência dos grandes centros industriais, a exemplo de economias, com pequenas extensões territoriais, menos recursos, mas que atingiram níveis competitivos de desenvolvimento, como Japão, Noruega e Singapura, entre outros. A literatura e os indicadores sociais e econômicos parecem demonstrar que a criação de fundos governamentais, impulsionados por políticas de gestão financeira arrojada, tem sido uma solução eficaz de justiça distributiva desses recursos, proporcionando altos índices de desenvolvimento, a exemplo do Fundo Soberano Norueguês.

\footnotetext{
${ }^{7}$ Outra concepção importante, que se confunde com a ideia de maldição dos recursos minerais, mas que pode ser aplicada também como exemplo de questão a ser enfrentada na gestão sustentável das receitas auferidas com a exploração de recursos naturais está assentada na experiência vivenciada pela Holanda com sua produção de gás natural na década de 1970, conhecida como doença holandesa (Dutch disease). Auty e Warhurst (1993) explicam a Dutch disease como a alta lucratividade da atividade minerária que potencializa a valorização do câmbio e reduz drasticamente a capacidade competitiva de mercado das atividades não-mineiras.

${ }^{8} \mathrm{O}$ conceito está aqui empregado no sentido proposto por Celso Furtado, para quem o desenvolvimento implica melhora da eficácia do sistema de produção, avanços sociais e satisfação de necessidades básicas do homem, como alimentação, habitação, saúde e educação, dentre outras, tudo isso compreendido a partir de um contexto cultural (FURTADO, 1964). Para superá-lo, o autor propõe que o Estado implemente políticas que fomentem a industrialização nacional, o avanço tecnológico e diversifiquem a produção econômica do país, ampliando as vantagens nos termos de troca e a superação (FURTADO, 2008).
} 


\section{Fundos de Equalização de Receitas (FER) como alternativa de desenvolvimento e justiça distributiva de riquezas para as futuras gerações}

No Pará, maior arrecadador estadual de CFEM desde 2019, os municípios com a maior produção mineral encontram-se nas regiões sul e sudeste do Estado, e dentre os que mais arrecadam royalties estão Canaã dos Carajás, Parauapebas, Marabá, como mostrado na seção anterior, além de Oriximiná e Paragominas. Esse rol deve aumentar na próxima década, de acordo com o Plano de Mineração do Estado proposto para o período entre 2014 a 2030 (SEICOM, 2014).

Nessa perspectiva, o estado é uma das principais fronteiras de expansão da mineração na Amazônia ${ }^{9}$. Dentre as principais jazidas localizadas em seu território, destaca-se o ferro da Serra de Carajás, na região sudeste do estado, reconhecido mundialmente não só pela quantidade, como pela qualidade de seus minérios (REYMÃO; LOUREIRO; MELLO NETO, 2019). Muito relevantes também são as reservas e a exploração de bauxita, manganês, cobre, ouro, níquel e caulim (CONGILIO, 2019).

As metas de crescimento da produção mineral estabelecidas para os municípios paraenses precisam ser vistas sob a ótica do desenvolvimento sustentável a fim de que a atividade mineradora potencialize seus efeitos positivos na região. Eggert (2000) destaca que, para que essa contribuição seja possível, deve-se considerar a riqueza mineral produzida, o fomento de outras atividades econômicas que garantam o bem-estar social quando não houver mais recursos e a aplicação de políticas públicas que controlem os possíveis efeitos negativos gerados pela mineração.

Nesse sentido, Hartwick (1977) sugere que o capital mineral seja substituído por outras formas de renovação do capital e pelo investimento em novas tecnologias. Uma forma de renovar o capital é a aplicação de parte dos royalties arrecadados para a formação de uma poupança que possa auferir anualmente, a título de juros compostos, um fundo de riqueza que garanta para as gerações futuras, receita equivalente às rendas minerais atuais. Esse tipo de gestão financeira é imprescindível à sustentabilidade e ao desenvolvimento das economias mineradoras.

\footnotetext{
${ }^{9}$ Com o avanço da COVID-19 e das incertezas na economia internacional, como as tensões entre Estados Unidos e China, elevou-se a preferência por ativos mais seguros como o ouro, cujo preço disparou e tem provocado uma corrida aos garimpos no estado. Em 4 de agosto de 2020 o preço da onça troy se elevou para US\$ 2 mil, muito superior a US\$ 1.560,67, cotação de janeiro de 2020 (INDEXMUNDI, 2020). Em moeda nacional, a cotação no começo do ano era de $\mathrm{R} \$ 195,96$ (1/01/2020), elevando-se para $\mathrm{R} \$ 342,10$ em 1 de setembro (BULLION RATES, 2020).
} 
Tomando como base o que propõe Rawls (2000), se houver convergência de vontade pública entre os atores políticos envolvidos, a adequação de fundos municipais, a partir da ideia dos fundos soberanos de riqueza já existentes, pode funcionar com veiculação financeira, maximização suas rendas minerais, desde que não precisem ser utilizados antes da exaustão dos minérios (FREITAS, 2008).

O uso dos Fundos de Equalização de Receitas (FER) para a gestão dos recursos da CFEM pode ser uma boa opção, devendo atender a pelo menos três finalidades: 1) impedir os efeitos negativos da "maldição dos recursos"; 2) transferir benefícios às futuras gerações; e 3) promover o princípio de equidade intergeracional, com a criação alternativas para a manutenção do nível de bem-estar socioeconômico após o esgotamento das reservas minerais (ENRIQUEZ, 2006).

Os FER são inspirados nos Fundos Soberanos de Riquezas (FSR) ${ }^{10}$, instrumentos financeiros adotados por alguns países que administram recursos provenientes, em muitos casos, da venda de recursos minerais e de petróleo. Eles podem ser de vários tipos, tendo alguns o objetivo de economizar recursos para as gerações futuras, podendo serem organizados como fundos de desenvolvimento em favor de objetivos socioeconômicos (TRUMAN, 2010).

Grande parte deles surgiu na partir da década de 1970, em países desenvolvidos com atividade petrolífera. As sociedades com maior desenvolvimento, criaram seus fundos depois de diversos debates que contaram com ampla participação popular, estabelecendo mecanismos de controle social e medidas de transparência pública. Esses procedimentos visam coibir a corrupção, a ineficiência e intervenção de interesses particulares locais ${ }^{11}$.

Embora existam alguns casos de má gestão desses fundos pelo mundo, a maioria tem se revelado eficaz na expansão dos volumes financeiros administrados. Como exemplos de sucesso, destaque-se os casos do Kuwait e o do Alasca, ambos criados em 1976. Tem-se também o fundo norueguês, que cresceu a partir dos anos 2000 e consiste num fundo de estabilização, mas que também possui o objetivo de conservação intergeracional de riqueza. Todos eles administram recursos provenientes da exploração petrolífera e gás natural e têm o propósito de melhorar a qualidade de vida das pessoas, em todos os aspectos, e potencializar suas economias locais.

\footnotetext{
${ }^{10}$ Em inglês, Sovereign Wealth Funds (SWF).

${ }^{11}$ Nem sempre obedecidos na gestão dessas entidades, como detalha o estudo de Truman (2010).
} 
Fundos como esses movimentam quantias que ultrapassam a marca dos bilhões de dólares, sendo que o fundo Norueguês já detém ativos que somam mais de 1 trilhão de dólares. Sua principal característica, como no caso da Noruega e do Alasca descritos em Enriquez (2006), é a gestão democrática em todos as fases de gerenciamento. A autora observa ainda que, além de estarem voltados para beneficiar as futuras gerações, atuam como fator de estabilização econômica, evitando os efeitos negativos ao desenvolvimento trazidos pela atividade de exploração dos recursos naturais.

No Brasil, a utilização de fundos públicos em nível municipal é recente e todos operam com royalties de petróleo. Em 2017 foi criado o Fundo Soberano de Maricá, com aporte inicial de 5\% da receita bruta, alterado depois para 15\%. Niterói, opera desde 2019 com um Fundo de Equalização de Receitas, para o qual são destinados $10 \%$ do valor arrecadado com participação especial do petróleo. O fundo soberano de Ilhabela, porém, tem sido o mais bem-sucedido dos fundos administrados até aqui e trabalha inicialmente com um aporte de $15 \%$ das receitas dos royalties, avançando para cumprir a meta estabelecida de atingir a marca de 2 bilhões de reais até 2028. Em 2019, o Espírito Santo criou o primeiro fundo soberano estadual o FUNSES - Fundo Soberano do Estado do Espírito Santo, além do e o Fundo de Obras e Infraestrutura Estratégica para o Desenvolvimento do ES que, juntos, deverão receber a monta variante entre $\mathrm{R} \$ 400$ a 500 milhões por ano (HEIDER, 2020).

Com a crescente importância da atividade mineral no Pará, seus impactos influenciam diretamente no desenvolvimento, vez que o estado e muitos de seus municípios mineradores enfrentam graves problemas ambientais e baixos índices socioeconômicos (CONGILIO, 2019). Muitos estudos destacam os preocupantes índices de desenvolvimento desses municípios e, se considerarmos que os benefícios disponíveis à geração atual são pequenos, preocupa a gravidade do legado a ser herdado pelas futuras gerações.

Levando em conta que esses recursos serão extintos, conclui-se também pelo fim da CFEM como receita pública, auferida apenas enquanto houver exploração. Logo, os entes subnacionais paraenses devem considerar que em todos os demais momentos, passados e futuros, não houve e nem haverá mais oportunidade de arrecadação de tal receita.

Chamar a atenção da administração pública para a criação de fundos municipais exclusivos para a gestão das receitas dessa Compensação, apesar de não ser tarefa fácil, não diminui sua urgência, haja vista que o tempo de vida útil das maiores jazidas paraenses, atualmente em processo de exploração, não chegará a cem anos (VALE, 2019). Assim, 
entende-se urgente a criação de fundos públicos que atendam às necessidades intra e intergeracionais dos municípios paraenses, projetando realizar investimentos de longo prazo.

Pensar em um fundo que reserve riqueza com fins de justiça intergeracional, implica, ainda, refletir sobre seu tratamento jurídico e fisco-contábil. Embora tenha havido divergência doutrinária acerca da classificação dos royalties no orçamento público brasileiro, a jurisprudência pátria, encerrou o debate, definindo-a como uma receita patrimonial, como explicita o acórdão do Supremo Tribunal Federal no RE 228800/DF (BRASIL, 2001).

Assim, considerando a Lei n. 4.320/64, que estabelece normas gerais para o controle orçamentário e de balanços da União e demais entes federativos, a CFEM é uma receita de capital (BRASIL, 1964), decorrente de conversão em espécie de bens e direitos (FERNANDES, 2013). Essa classificação da lei parece pretender a salvaguarda do uso desses royalties, nos princípios que orientam o presente estudo desde o início, uma vez que nessa classificação busca conectar seu uso em despesas de capital, embora não haja uma norma que obrigue nenhuma vinculação.

O tratamento dado por ela parece querer prevenir que os royalties sejam empregados como despesas de custeio da máquina pública, posto que nesse critério, alimenta-se ainda mais a minério-dependência, confirmando a tese da maldição dos recursos naturais finitos, numa conduta contrária a qualquer possibilidade de se promover a justiça intergeracional, pois assim transfere-se de forma irresponsável um ônus de proporções imprevisíveis para as futuras gerações (ENRIQUEZ, 2018).

Orientar a classificação dos royalties minerais oriundos de fontes não renováveis como receitas de capital induz sua destinação para despesas de capital, que podem ser trabalhadas a longo prazo, permitindo as perdas com a exploração sejam convertidas em ativos de sustentabilidade, sendo possível aplicar um conduta ética de responsabilidade entre gerações como proposta por John Rawls, por meio de uma poupança que expresse a sensibilidade das presentes gerações em promover justiça àqueles que não tem hoje como se defender dos encargos gerados pelo esgotamento dessas riquezas infungíveis.

\section{Considerações finais}

O caminho percorrido no presente estudo buscou sustentações de análise em dois pilares de discussão que possibilitaram apontar a necessidade de criação de fundos de 
equalização de receitas (FER) em municípios mineradores no Pará, provenientes de fontes minerais não renováveis, como estratégia de formação de reservas de riqueza com fins de prover justiça intergeracional.

Esses pilares foram: (i) a importância da sustentabilidade e da noção de justiça intergeracional, a partir não apenas da consciência de exaustão de alguns recursos minerais, mas das experiências ambientais e socioeconômicas e pela doutrina multidisciplinar acerca do assunto, mas também das importantes contribuições trazidas nas formulações teóricas erguidas por John Rawls em sua teoria da justiça; e (ii) o uso de políticas públicas como instrumento de positivo de governança voltada ao contexto de entes subnacionais brasileiros, com fins de superação da condição de subdesenvolvimento, rumo ao desenvolvimento sustentável.

A finalidade, portanto, é a otimização das rendas auferidas pelos municípios paraenses a título de CFEM, com a formação de uma reserva de capital, instrumentalizada por um fundo capaz de potencializar essa arrecadação e que funcione como poupança compartilhada intergeracionalmente.

A partir dos princípios igualitários de justiça de Rawls (2000) e da ideia de justiça intergeracional de Tremmel (2009), chamou-se atenção de salvaguardar os interesses das gerações futuras, os quais devem ser considerados nas tomadas de decisões públicas, como a formulação de políticas públicas em municípios em que a dinâmica é dependente de recursos finitos, como os minerais.

A alta dependência das receitas de CFEM em municípios pareaenses, a exemplo de Canãa dos Carajás e Parauapebas, é insustentável, apesar da riqueza de seus recursos minerais, uma vez que essa renda é categoricamente finita.

\section{Referências}

AGÊNCIA NACIONAL DE MINERAÇÃO (ANM). Arrecadação CFEM. Brasília: Agência Nacional de Mineração, 2020. Disponível em: http: www.sistemas.dnpm.gov.br/arrecadacao/ extra/Relatorios/arrecadacao_cfem.aspx. Acesso em: 21 mai. 2020.

AUTY, Richard; WARHURST, Alyson. Sustainable development in mineral exporting economies. Resources Policy, v. 19, n. 1, p. 14-29, 1993. 
BERCOVICI, Gilberto. Direito econômico do petróleo e dos recursos minerais. São Paulo: Quartier Latin, 2011.

BRASIL. Constituição da República Federativa do Brasil de 1988. Brasília, DF:

Presidência da República, [1988]. Disponível em:

http://www.planalto.gov.br/ccivil_03/Constituicao/CConstituiçao.htm. Acesso em: 1 jun. 2020.

BRASIL. Lei n. 13.540, de 18 de dezembro de 2017. Altera as Leis $n^{\circ} 7.990$, de 28 de dezembro de 1989, e 8.001, de 13 de março de 1990, para dispor sobre a Compensação Financeira pela Exploração de Recursos Minerais (CFEM). Brasília: Câmara dos Deputados, [2017]. Disponível em: http://www.planalto.gov.br/ccivil_03/Ato2015-

2018/2017/Lei/L13540.htm\#: :text=Altera\%20as\%20Leis\%20n\%20\%C2\%BA,de\%20Recurs os\%20Minerais\%20(CFEM). Acesso em: 11 jun. 2020.

BRASIL. Lei Federal $\mathbf{n}^{\mathbf{0}}$ 4.320, de 17 de março de 1964. Estatui Normas Gerais de Direito Financeiro para elaboração e controle dos orçamentos e balanços da União, dos Estados, dos Municípios e do Distrito Federal. Disponível em: http://www.planalto.gov.br/ccivil_03/Leis/L4320.htm. Acesso em: 20 jul. 2020.

BRASIL. Supremo Tribunal Federal (STF). Recurso Extraordinário 228800/DF. Relator Ministro Sepúlveda Pertence. Primeira Turma. Data de Julgamento: 25/02/2001. Data de Publicação: DJ 16/11/2001, p. 21.

BULLION RATES. Preços dos metais preciosos. 2020. Disponível em: https://pt.bullionrates.com/gold/BRL/2020-9-history.htm. Acesso em: 12 set. 2020.

CONGILIO, Celia et al. Mineração, trabalho e conflitos amazônicos no sudeste do Pará. Marabá, PA: iGuana, 2019. Disponível em: https://br.boell.org/sites/default/files/202004/1562059330971_MinerTrabConflitos_ebook-1.pdf\#page=98 . Acesso em: 15 abr. 2020.

EGGERT, Roderick G. Sustainable Development and the Mineral Industry. In: James M. Otto e John Corde (eds) Sustainable Development and the Future of Mineral Investment. Paris: United Nations Environnment Programme, 2000, cap. 2. Disponível em: https://wedocs.unep.org/rest/bitstreams/13309/retrieve. Acesso em: 01 ago. 2020.

ENRIQUEZ, Maria Amélia Rodrigues da Silva. Equidade intergeracional na partilha dos benefícios dos recursos minerais: a alternativa dos Fundos de Mineração. In: Revista Iberoamericana de Economia Ecológica. Vol. 5: 61-73, disponível em:<www.redibec.org/IVO/rev5_05. Pd> Acesso em: 04 set.2020

ENRIQUEZ, Maria Amélia Rodrigues da Silva. Maldição ou dádiva? Os dilemas do desenvolvimento sustentável a partir de uma base mineira. 2007. $449 \mathrm{f}$. Tese (Doutorado em Desenvolvimento Sustentável) - Universidade de Brasília, Brasília, 2007. Disponível em: https://repositorio.unb.br/handle/10482/6417 . Acesso em: 02 jun 2020.

ENRIQUEZ, Maria Amélia Rodrigues da Silva et al. Contradições do desenvolvimento e o uso da CFEM em Canaã dos Carajás (PA). Rio de Janeiro: Instituto Brasileiro de Análises 
Sociais e Econômicas, 2018. Disponível em: https://ibase.br/pt/noticias/uso-da-cfem-emcanaa-dos-carajas-pa-e-revelado-em-pesquisa/ . Acesso em: 02 jun. 2020.

FERNANDES, Andressa Guimarães Torquato. Direito financeiro aplicado ao setor do petróleo. Tese (Doutorado em Direito Financeiro) - Faculdade de Direito da Universidade de São Paulo. 2013. Disponível em: https://www.teses.usp.br/teses/disponiveis/2/2133/tde-22082014092712/publico/ANDRESSA_TORQUATO_TESE_VERSAO_FINAL.pdf. Acesso em: 03 ago 2020.

FERREIRA, Ilana Dalva; IMBROISI, Denise. A equidade intergeracional e a taxa de desconto em impactos ambientais de longo prazo. Nova economia, v. 28, n. 3, p. 913-942, 2018. Disponível em: https://www.scielo.br/pdf/neco/v28n3/1980-5381-neco-28-03-0913.pdf. Acesso em 25 jul. 2020.

FIGUEIRÔA, S. F. D. M. "Metais aos pés do trono": exploração mineral e o início da investigação da terra no Brasil. Revista USP, São Paulo, n. 71, p. 10-19, set. nov., 2006.

FINANÇAS DO BRASIL. Dados Contábeis dos Municípios. Brasília: FINBRA: Tesouro Nacional. Disponível em: www.tesourotransparente.gov.br. Acesso em: 2 jun. 2020.

FREITAS, Paulo Springer de. Rendas do petróleo: questão federativa e instituição de Fundo Soberano. Nova fronteira do petróleo: os desafios do pré-sal. Trabalho apresentado no $4^{\circ}$ Fórum Senado Debate Brasil. Brasília, 2008.

FURTADO, Celso. O desenvolvimento recente da economia venezuelana. In: Ensaios sobre a Venezuela: subdesenvolvimento com abundância de divisas. Caracas: Editora Contraponto, p. 118-135, 2008.

FURTADO, Celso. Dialética do desenvolvimento. Rio de Janeiro: Fondo de Cultura, 1964.

HEAL, Geoffrey. Are oil producers rich?. In: HUMPHREYS, Macartan; SACHS, Jeffrey D.; STIGLITZ, Joseph E. (Org.). Escaping the resource curse. New York: Columbia University Press, 2007.

GOSSERIES, Axel. On future generations future rights. The Journal for Political Philosophy, v. 16, n. 4, p. 446-474, 2008. Disponível em: https://onlinelibrary.wiley.com/doi/abs/10.1111/j.1467-9760.2008.00323.x . Acesso em: 26 jul 2020.

GOSSERIES, Axel. A Justiça Intergeracional e a metáfora do refúgio de montanha. Philosophica, Lisboa, p. 121-141, 2011. Disponível em: https://cdn.uclouvain.be/public/Exports\%20reddot/etes/documents/Refugio_de_Montanha.pdf . Acesso em: 15 jul 2020.

HARTWICK, John M. Intergenerational equity and the investing of rents from exhaustible resources. The American Economic Review, v. 67, n. 5, p. 972-974, dez. 1977. Disponível em: 
https://www.uio.no/studier/emner/sv/oekonomi/ECON4925/h16/pensumliste /hartwick intergenerational-equity-and-the-investing-of-rents-from-exhaustible-resources.pdf . Acesso em: 27 jul 2020.

HEIDER, Mathias. Royalties do petróleo: lições da Noruega II. Revista Inthemine. Ano $\mathrm{XV}, \mathrm{n}^{\circ}$ 84. 2020. Disponível em: https://www.inthemine.com.br/site/edicao-no-84/ . Acesso em: 07 set. 2020

INDEXMUNDI. Commodity Prices. Disponível em https://www.indexmundi.com/pt/pre\%C3\%A7os-de-mercado/?mercadoria=min\%C3\%A9riode-ferro\&meses=60. Acesso em 12 set. 2020.

KARL, Terry L.. Ensuring fairness: the case for a transparent fiscal social contract. In: HUMPHREYS, Macartan; SACHS, Jeffrey D.; STIGLITZ, Joseph E. (Org.). Escaping the resource curse. New York: Columbia University Press, 2007. Disponível em: http://policydialogue.org/publications/working-papers/ensuring-fairness-the-case-for-atransparent-fiscal-social-contract/. Acesso em: 27 jul 2020.

KELSEN, Hans. O que é justiça? A justiça, o direito e a política no espelho a ciência. 3. ed. Tradução: Luís Carlos Borges. São Paulo: Martins Fontes, 2001.

LEWIS JUNIOR, S. R. Development problems of the mineral-rich countries. In: SYRQUIN, M.; TAYLOR, L.; WESTPHAL, Larry E. (ed). Economic structure and performance: essays in the honor of Hollis B. Chenery. Orlando, FL: Academic Press. Inc, p. 157-177, 1984. Disponível em:

https://www.sciencedirect.com/science/article/pii/B9780126800609500155 . Acesso em: 24 jul 2020.

RAWLS, J. A teoria da justiça. Tradução: Almiro Pisseta, Lenita M. R. Esteves. Martins Fontes, São Paulo, 2000.

REYMÃO, Ana Elizabeth Neirão; LOUREIRO, João Gustavo Gouveia; MELLO NETO, Ridivan Clairefont de Souza. A CFEM e as Políticas Públicas nos Maiores Municípios Mineradores de Paraenses. In: DIAS, J. C.; BRITO FILHO, J. C. D.; ARAÚJO, J. H. M. (coord.). Direito e Desenvolvimento na Amazônia. Santa Catarina: Qualis, 2019. p. 9-30. Disponível em: https://gpminamazonia.blogspot.com/2020/04/livro-direito-edesenvolvimento-da.html. Acesso em: 29 mai. 2020.

ROCHA, Joaquim Freitas da. Breves reflexões sobre responsabilidade colectiva e finanças públicas. In: ROCHA, Joaquim Freitas da (Coord.). Anuário publicista da Escola de Direito da Universidade do Minho - Responsabilidade e cidadania. Braga: Universidade do Minho, 2012.t. I, ano 2012.

SEICOM - SECRETARIA DE ESTADO DE INDÚSTRIA, COMÉRCIO E MINERAÇÃO. Plano de Mineração do Estado do Pará 2014-2030. 2014. Disponível em: https://issuu.com/antoniojunior34/docs/plano_de_minera___o_par_. Acesso em: 05 de agosto de 2020. 
SCAFF, Fernando Facury. Royalties do petróleo, minério e energia: aspectos constitucionais, financeiros e tributários. $1^{\text {a }}$ Ed. São Paulo: Revista dos Tribunais, 2014.

SERAGELDIN, Ismail. Sustainability and the wealth of nations: first steps in an ongoing journey. Preliminary draft for discussion, Presented at the Third Annual World Bank Conference on Environmentally Sustainable Development, September. 1995.

TREMMEL, Joerd. Chet. A Theory of Intergenerational Justice. London: Routledge, 2009.

TRUMAN, Edwin. Sovereign wealth funds: Threat or salvation?. Peterson Institute, 2010.

VALE S.A. Formulário 20F: relatório técnico. Rio de Janeiro, 2019. Disponível em: http://www.vale.com/PT/investors/information-market/annualreports/20f/20FDocs/Vale\%2020-F\%202019_p.pdf . Acesso em: 10 jun. 2020

ZAMBAM, Neuro José; BOFF, Salete Oro. A compreensão de sustentabilidade para uma política de desenvolvimento a partir da teoria de Rawls. Revista Brasileira de Estudos Políticos. Belo Horizonte, n. 106, jan./jun. 2013. pp. 215-239. Disponível em: https://www.researchgate.net/publication/271265838_A_compreensao_de_sustentabilidade_p ara_uma_politica_de desenvolvimento_a_partir_da_teoria_de_Rawls_- DOI_109732P003471912013v106p215. Acesso em: 04 ago.2020. 